\title{
Symptoms of lactose intolerance - Forget about the cause?
}

\author{
Johane P Allard MD FRCPC
}

\begin{abstract}
A majority of the world's population maldigests lactose, and the resultant lactose malabsorption may cause symptoms of flatulence, diarrhea and abdominal discomfort. These symptoms are affected by several factors (1). In addition to the amount of lactose ingested, dietary factors such as concomitant meal ingestion, fermented and nonfermented products, fat content and food consistency have been shown to influence symptoms. In addition, gastrointestinal physiological factors such as gastrointestinal transit, intestinal lactase activity, visceral sensitivity, composition and adaptation of colonic microflora, underlying functional bowel disorders and symptom perception play a role. Taking into account the complex interactions among all of these variables, it is not surprising to find marked inter- and intraindividual differences in symptoms of lactose intolerance. This makes the field of lactose intolerance more challenging to study and may explain the variability of individual response to different dietary manipulations or therapeutic interventions.

As reported in this issue of The Canadian Journal of Gastroenterology, Szilagyi et al (pages 581-587) examined the effect of loperamide as a potential agent to reduce symptoms related to lactose intolerance. Loperamide $8 \mathrm{mg}$ significantly improved symptom scores after lactose challenge; this result was not statistically different from that found when seven lactase tablets were used. However, 4 and $12 \mathrm{mg}$ doses did not produce a significant effect. If the beneficial effect of $8 \mathrm{mg}$ loperamide is thought to occur via slower intestinal transit, it is unclear why $12 \mathrm{mg}$ would not be at least as effective in reducing symptoms. The authors discuss this issue in
\end{abstract}

detail. However, one possible explanation not mentioned in the discussion is the possible side effects from the drug itself, where abdominal discomfort, bloating and cramps would have been indistinguishable from symptoms of lactose intolerance.

This 'therapeutic approach' to lactose intolerance addresses the concept that prolonging intestinal transit may improve symptoms by increasing mucosal contact time, enhancing lactose hydrolysis and absorption, and in turn reducing the delivery of undigested carbohydrates through the ileocecal valve. However, benefits from loperamide may also occur because of its effect on an underlying irritable bowel syndrome, where visceral sensitivity and motor abnormalities may affect symptoms. According to recent studies, both lactose digesters and maldigesters can experience symptoms after ingestion of very low lactose or lactose-free milk $(2,3)$. This suggests that many of the symptoms experienced by lactose maldigesters are not related to lactose digestion. Furthermore, in a large Finnish study, subjective lactose intolerance was strongly related to irritable bowel syndrome in addition to lactose maldigestion (4).

Should lactose intolerance be treated? In populations with a high proportion of lactose maldigesters, milk has been used successfully to treat malnutrition, with only temporary increases in symptoms (5). In Szilagyi's study, among the 19 subjects studied with abnormal hydrogen breath test results, only six actually noted symptoms when consuming dairy products. In fact, lactose maldigesters consuming dairy products on a regular basis may not be the ones with significant symptoms. There is evidence that these symptoms may be 
temporary for a high proportion of lactose maldigesters and that the mechanisms reside in the adaptation of the colonic microflora during prolonged lactose exposure (2). This adaptation has the potential to decrease flatulence and diarrhea, and may allow lactose maldigesters to tolerate very large doses of lactose when this sugar is consumed regularly!

Therefore, the whole concept of lactose intolerance may be overrated. Although current therapies focus on improving digestion of lactose in the upper gastrointestinal tract, loperamide may have a role in alleviating symptoms whether due to lactose intolerance or irritable bowel syndrome. However, it seems that adaptation of the colonic flora to regular lactose consumption is a simpler and less expensive solution for subjects who wish to consume relatively large quantities of dairy products regularly, either for enjoyment or for health benefit. This suggests that perhaps the best way to treat lactose intolerance is to forget about the cause!

\section{REFERENCES}

1. Vesa TH, Marteau P, Korpela R. Lactose intolerance. J Am Coll Nutr 2000;19(2 Suppl):165S-75S.

2. Hertzler SR, Savaiano DA. Colonic adaptation to daily lactose feeding in lactose maldigesters reduces lactose intolerance. Am J Clin Nutr 1996;64:232-6.

3. Suarez FL, Savaiano DA, Levitt MD. A comparison of symptoms after the consumption of milk or lactose-hydrolyzed milk by people with self-reported severe lactose intolerance. N Engl J Med $1995 ; 333: 1-4$

4. Vesa TH, Seppo LM, Marteau PR, Sahi T, Korpela R. Role of irritable bowel syndrome in subjective lactose intolerance. Am J Clin Nutr 1998;67:710-5.

5. Scrimshaw NS, Murray EB. The acceptability of milk and milk products in populations with a high prevalence of lactose intolerance. Am J Clin Nutr 1988;48(4 Suppl):1079-159. 


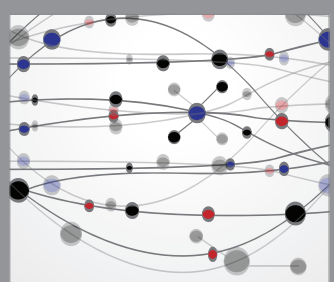

The Scientific World Journal
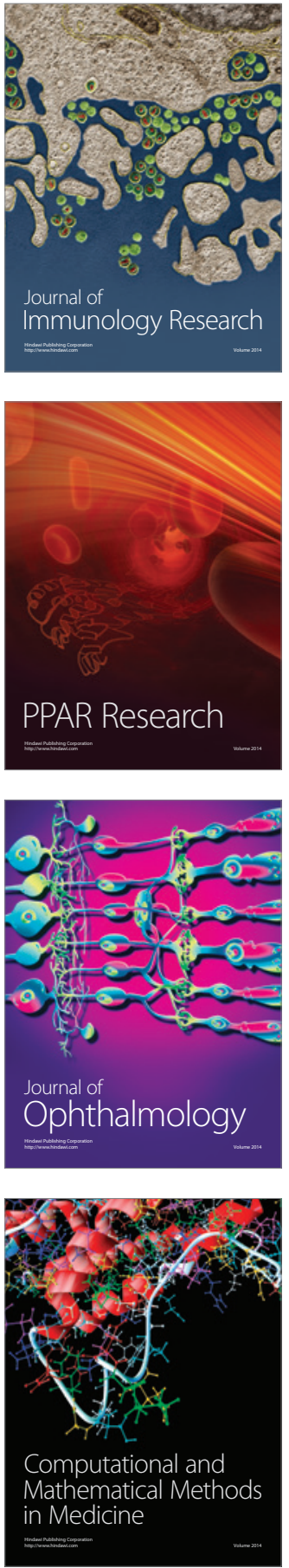

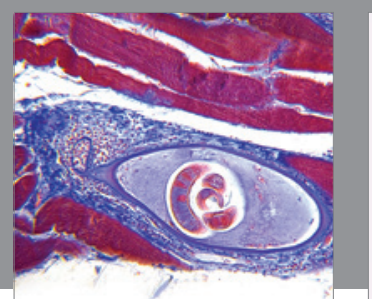

Gastroenterology Research and Practice

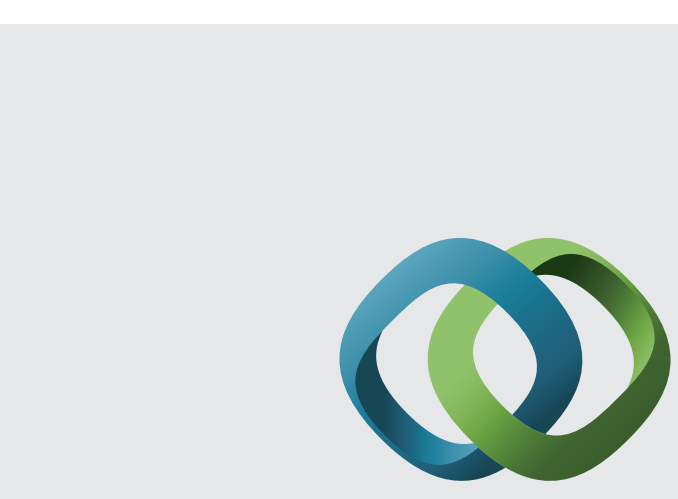

\section{Hindawi}

Submit your manuscripts at

http://www.hindawi.com
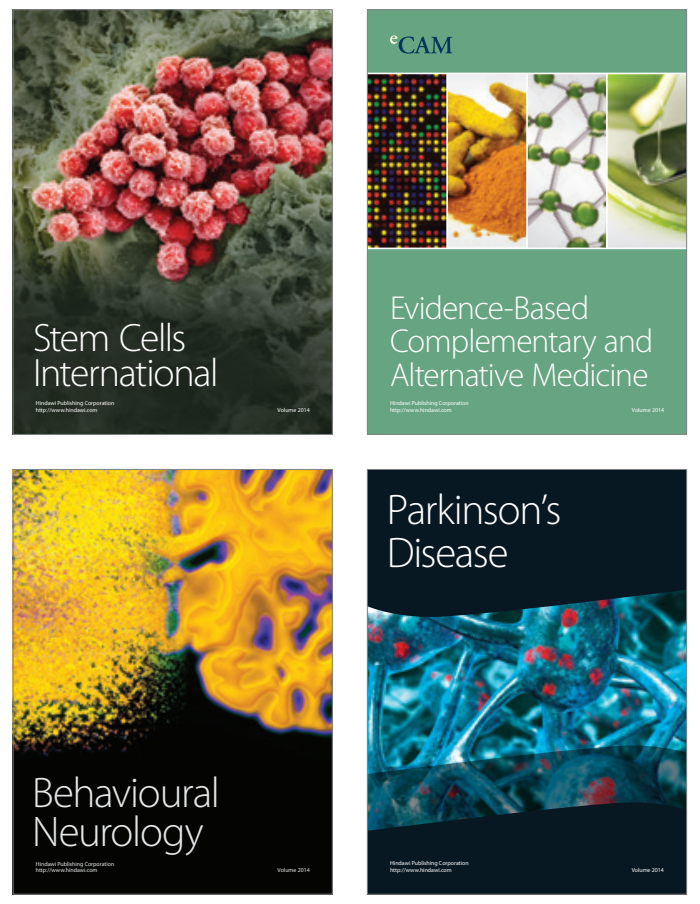
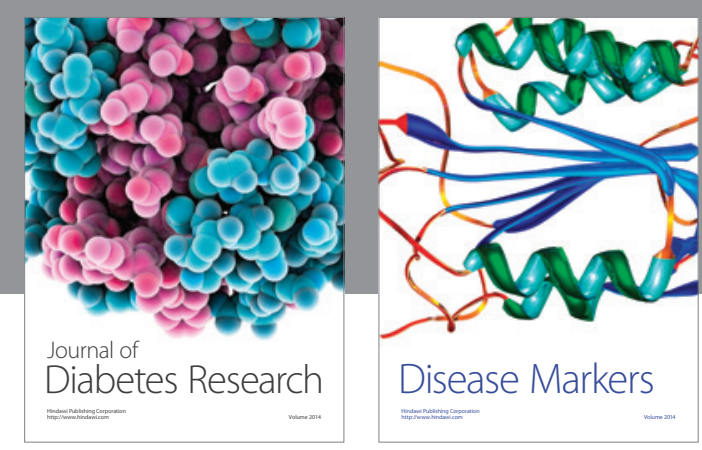

Disease Markers
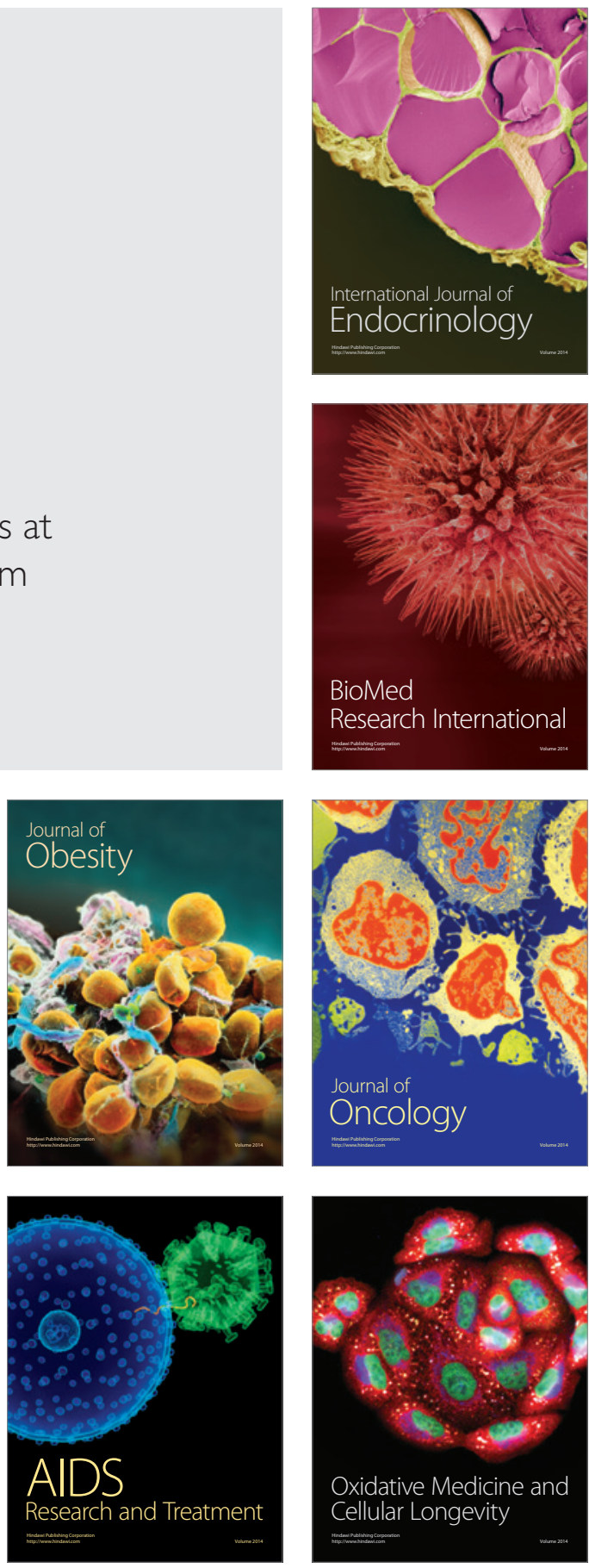